Andrew Lorrey also illustrated a synoptic pressure reconstruction approach using speleothems and low resolution data. These reconstructions will form an important means of independently supporting low frequency trends and variability identified from the high-resolution material.

To round off the second day of presentations, Steven Phipps provided a thought-provoking discussion of the role of modeling in understanding the climate of the last 2000 years. He provided an example of evaluating the stability of regional teleconnections and influence of different climate forcings using simulations from the CSIRO Mk3L model.

The workshop wrapped up on a very productive note with the development of a proposed list of 15 papers for consideration in the Journal of Climate Aus2k special issue, and a clear direction forward to deliver Australasia's best available science for the Regional 2k global synthesis.

\section{Acknowledgements}

The meeting organizers would like to thank PAGES, Rio Tinto Iron Ore, the Australian Department of Climate Change and Energy Efficiency and the University of Western Australia.

\section{References}

Cook, E., Woodhouse, C., Eakin, M., Meko, D. and Stahle, D., 2004: LongTerm Aridity Changes in the Western United States, Science, 306 1015-1018.

Cook, E.R., Anchukaitis, K.J., Buckley, B.M., D'Arrigo, R.D., Jacoby, G.C. and Wright, W.E., 2010: Asian Monsoon Failure and Megadrought During the Last Millennium, Science, 328(5977): 486-489.

Cullen, L. and Grierson, P., 2009: Multi-decadal scale variability in autumn-winter rainfall in south-western Australia since 1655 AD as reconstructed from tree rings of Callitris columellaris, Climate Dynamics, 33(2-3): 433-444.

Neukom, R., et al., 2010a: Multi-centennial summer and winter precipitation variability in southern South America, Geophysical Research Letters, 37: doi: 10.1029/2010GL043680.

Neukom, R., et al., 2010b: Multiproxy summer and winter surface air temperature field reconstructions for southern South America covering the past centuries, Climate Dynamics, doi:10.1007/ s00382-010-0793-3.

\title{
The first Euro-Med2k regional workshop: Review of current knowledge, available data and plans for multproxy integration \\ EURO-AED2k
}

\section{Alcalá de Henares, Spain, 22-24 November 2010}

\section{Jürg Luterbacher ${ }^{1}$, D. McCarroll ${ }^{2}$, D. Fleitmann ${ }^{3}$, F.J. Gonzalez-Rouco ${ }^{4}$, E. Zorita ${ }^{5}$, S. Salcedo ${ }^{6}$ and B. Vinther ${ }^{7}$}

'Department of Geography, Justus Liebig University of Giessen, Germany; juerg.luterbacher@geogr.uni-giessen.de

${ }^{2}$ School of the Environment and Society, Swansea University, Wales, UK; ${ }^{3}$ Oeschger Centre for Climate Change Research and Institute of Geological Sciences, University of Bern, Switzerland; ${ }^{4}$ Department of Astrophysics and Atmospheric Sciences, Complutense University-IGEO, Madrid, Spain; ${ }^{5} \mathrm{Helmholtz}$ Centre for Materials and Coastal Research, Germany; ${ }^{6}$ Superior Polytechnic School, University of Alcalá, Madrid, Spain; ${ }^{7}$ Centre for Ice and Climate, Niels Bohr Institute, University of Copenhagen, Denmark

Focus 2 (Regional Climate Dynamics) of PAGES places a strong emphasis on regional climate studies that consider past climate dynamics on seasonal to millennial timescales and (sub-) continental or ocean-basin spatial scales (PAGES, 2009).
The first Europe/Mediterranean 2k (EuroMed2k) regional meeting was held in Alcalá de Henares, close to Madrid, and brought together specialists working in different fields related to proxy data, statistical climate reconstructions and data modeling comparison. Discussions focused firstly on current knowledge and availability of documentary sources as well as on seasonally to multidecadally resolved terrestrial and marine archives (Fig. 1) covering the past 2000 years ( $2 \mathrm{ka}$ ) in

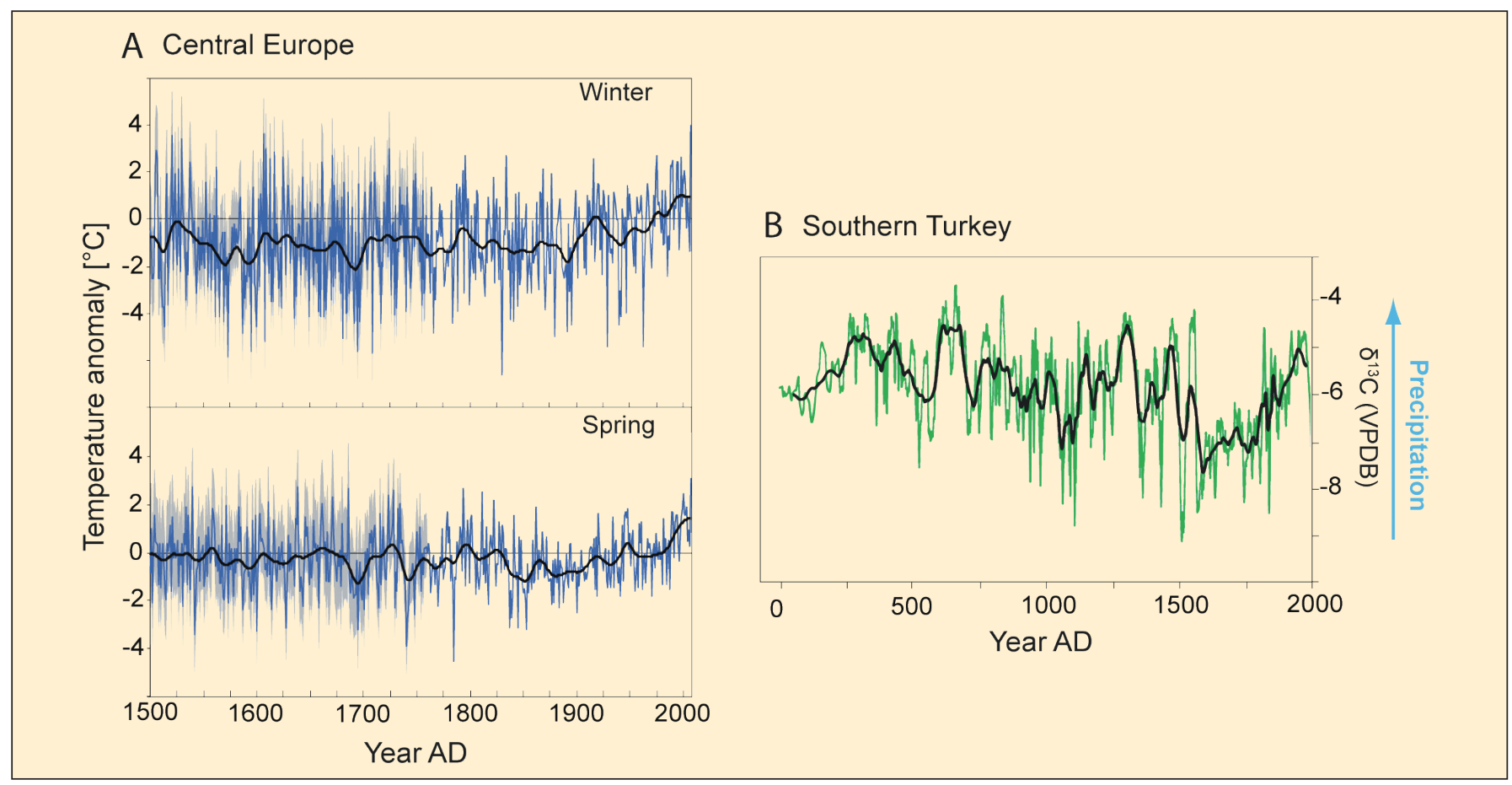

Figure 1: A) Winter and Spring Central European temperature reconstructions AD 1500-2007 based on documentary indices $1500-1759$ and instrumental measurements 1760-2007 (Dobrovolný et al., 2010). Temperatures are expressed as anomalies from the 1961-1990 average and completed with Gaussian low-pass filter (30 years window). The error bands are approximate $95 \%$ confidence intervals. B) Stalagmite $\delta^{13} \mathrm{C}$ record of effective moisture from Kocain Cave in Southern Turkey (Göktürk et al., submitted). 
the European-Mediterranean region. The participants discussed proxy records with emphasis on their climatic interpretation and the suitability for their integration into the regional reconstruction. Particular issues that were addressed included the handling of differently resolved proxies, target variables, seasonality, preservation of low- and high-frequency variability, replication, "expert knowledge" and calibration/verification. An extended discussion took place on how proxy data should be most effectively collected. It was agreed that the community should collect only published data (using both raw and quantified analyses) from each of the different archives, with a full estimate of the uncertainties included. Importantly, objective criteria for the final selection of records must be developed prior to the generation of final statistically based reconstructions (in consultation with other regional $2 \mathrm{k}$ groups; criteria having been presented by two representatives of the Arctic2k group). Qualitative data will also be utilized to cross-check against the climate variability reconstructed from higher resolution records. As a starting point, the group was encouraged to develop a EuroMed2k metadatabase on the project's website, to develop an inventory of the records that are currently available and/or being actively developed in the Euro-Med region. Discussions also focused on different statistical methods used in paleoclimatology that can integrate multiproxy data.

A better understanding of the strengths and weaknesses of established and new reconstruction methods and the behavior of different climate proxies was considered essential to reduce uncertainties and biases. A variety of available methods were presented including Bayesian hierarchical modeling and Neural Networks using pseudo-proxy data. These methods provide an estimate of the full covariance structure of the temperature and hydrological reconstructions, but need to be tested first using real proxy data from the Europe-Mediterranean region. A presentation provided new millennial-length coupled climate model results and ways to compare continental-scale multiproxy climate reconstructions with coupled paleoclimate model output.

The group agreed to write a peer reviewed paper including a comprehensive assessment of proxy data availability from the European-Mediterranean area, and a critical evaluation of their strengths, weaknesses, challenges and opportunities for climate reconstructions. To involve the wider community in sharing data and participating in the initiative, specialists on different archives will be approached. First results and a promotion of the initiative will be presented in the PAGES $2 \mathrm{k}$ session at the INQUA Congress in Bern in late July 2011. In parallel, data collected and published by the EU project MILLENNIUM (www.millenniumproject.net) and the ESF project MedClivar (http://www.medclivar. eu/) will be used to test different statistical methods. Preliminary reconstruction results from the European-Mediterranean area will feed a joint " $2 \mathrm{k}$ Consortium" publication, (anticipated submission in late 2011). These results might contribute to the "regional assessment" of IPCC AR5. At a later stage, other initiatives of the group will include a data-model comparison paper using the new statistics-based reconstructions from Europe-Mediterranean covering the past 2 ka with new paleoclimate runs that will become available. The second Euro-Med2k workshop will be held in early 2012.

\section{References}

Dobrovolný, P., et al., 2010: Temperature reconstruction of Central Europe derived from documentary evidence since AD 1500, Climatic Change, 101: 69-107.

Göktürk, O.M., Fleitmann, D., Badertscher, S., Cheng, H., Edwards, R.L. and Tüysüz, 0. 2011: A late-Holocene record of paleoclimate from the Kocain cave in southern Turkey, submitted.

PAGES, 2009: Science Plan and Implementation Strategy, IGBP Report No. 57, IGBP Secretariat, Stockholm.

\title{
Advancing North American climate field reconstructions: Data sources, methods development and comparisons
}

\section{$1^{\text {st }}$ PAGES North America-2k Workshop, Flagstaff, USA, 8-10 May 2011}

\author{
Henry F. Diaz' ${ }^{1}$, E.R. WAHL ${ }^{2}$ and D.S. Kaufman ${ }^{3}$ \\ 'University of Colorado, Cooperative Institute for Research in Environmental Sciences, Boulder, USA; Henry.F.Diaz@noaa.gov \\ ${ }^{2}$ National Oceanic and Atmospheric Administration/National Climatic Data Center, Boulder, USA; ${ }^{3}$ Northern Arizona University, Flagstaff, USA
}

The principal goal of the North America 2k (NAm2k) Working Group (WG) is to synthesize high-resolution, proxy-based climate reconstructions for North America for the past 2000 years. The motivation is to enhance our understanding of the patterns of natural variability of climate in North America and possible forcing mechanisms, and for comparison with high-resolution Earth System Models.

We assembled a group of climate and paleoclimate experts (see www.pages. unibe.ch/workinggroups/namerica2k for details of members) to provide an initial assessment of our capacity to carry out the task of producing a high-resolution reconstruction of key North American cli- mate variables with at least a decadal resolution. The WG considered the following: - Identification of the key paleoclimate time series available for analysis.

- Evaluation of available spatiotemporal reconstructions of the key regional climatic parameters (surface air temperature and precipitation) and reconstructions of large-scale circulation modes (e.g., AMO, PDO, ENSO).

- Validation of reconstructions through statistical methods and comparison with existing hemispheric- to globalscale multiproxy based reconstructions and climate model simulations.

The following are the major findings and action items from this workshop:
1) By far the most numerous climate proxy records for North America are tree-ring data (see e.g., Fig. 1), which are available at annual or better resolution over much of the continent. These records are sensitive to both temperature and precipitation variability. There is an extensive amount of peer-reviewed literature from more than 50 years of climatic reconstruction work that can be used for the NAm2k effort. The North America Drought Atlas (Cook et al. 2004) is currently the most extensive, high-temporal resolution paleoclimate record available for North America. It consists of gridded summer (JJA) Palmer Drought Severity Index values for the past 500-2000 years, with a trend towards 